\title{
A Conventional and Micro wave Assisted Synthesis of 3-(3-(4-chlorophenyl)acryloyl)-2H-chromen-2-one Using Eco-Friendly Catalyst And Its Characterisation
}

\author{
D Jayaseelan ${ }^{1}$, M Ganapathi ${ }^{2}$ and S Guhanathan ${ }^{1 *}$ \\ ${ }^{1} P G$ \& Research Department of Chemistry, Muthurangam Government Arts College (Autonomous), Vellore, Tamilnadu, India \\ ${ }^{2} P G$ \& Research Department of Chemistry, Government Arts College, Tiruvannamalai, Tamilnadu, India
}

Received: September 25; Accepted: October 5, 2015; Published: October 25, 2015

*Corresponding author: S.Guhanathan, $P G$ \& Research Department of Chemistry, Muthurangam Government Arts College (Autonomous), Vellore, Tamilnadu, India. E-mail: sai_gugan@yahoo.com

\begin{abstract}
A convenient and efficient method of Chloro substituted (3-(4-chlorophenyl) acryloyl)-2H-chromen-2-one derivatives were achieved by following two stage .In a first stage 3-Acetyl coumarin were synthesised by a Microwave assisted Method. The mixture of salicyaldehyde and ethyl aceto acetate by a Von Pechmann condensation using $\mathrm{Zn}\left[(\mathrm{L})-\right.$ Proline $_{2}$ as solvent free catalyst. The Organo metallic Catalyst Zinc amino complex was prepared by adding tri ethyl amine and L-Proline in Methanol followed by adding zinc acetate,after completion of reaction getting white $\mathrm{Zn}[(\mathrm{L})$ Proline $]_{2}$ complex .In a second stage 3 -acetyl coumarin and 4-chloro benzaldehyde were allowed to react with PEG-600 as a solvent by Claisen-Schmidt condensation which gives 3-(3-(4-chlorophenyl) acryloyl)-2H-chromen-2-one by green chemistry approach. In Previous methods of synthesis both conventional and microwave irradiation. The progress of the reaction was monitored by TLC and separated the compound using column chromatography. The synthesized compound structures were identified and confirmed by UV-Visible, FT-IR and ${ }^{1} \mathrm{H}$ NMR and Mass spectral analysis respectively.
\end{abstract}

Keywords: Pechmann Condensation; Coumarins; Organo Metallic Catalyst; PEG-600; MWI; Green Synthesis

\section{Introduction}

Coumarins have been synthesized as a well-known naturally occurring heterocyclic compounds isolated from various plants. They belong to the family of lactones having 1-benzo pyran-2one system [1]. Coumarin is a versatile pharmacophore which exhibits wide variety of biological activities [2] like antibacterial [3-4] and antimicrobial [5]. Coumarins have been synthesized by several routes including pechmann [6], Perkin [7], knoevenagel [9], reformatsky [10] and Wittig [11] reactions.

The century-old Pechmann reaction is widely used method for preparing Coumarins [12] and it is an example of exothermic reaction. A commonly used protocol for conducting this reaction involves heating together a mixture of a salicyaldeyde (1) and beta-keto ester such ethyl aceto acetate (2) and a large amount of sulphuric acid [6] as a condensing agent. The major product(4) obtained in low to good yield is a substituted coumarin.In Pechmann reaction most of the researcher used acidic agents, such as chloro sulphuric acid [12], melamine formaldehyde resin supported $\mathrm{H}+$ ion catalyzed [14], ionic liquid catalyzed [15], oxalic acid catalyzed [16], silica triflate catalyzed, heterogeneous catalyst, zirconium supported catalyst etc. Recently, Pechmann reaction has been carried out by using $\mathrm{CuFe}_{2} \mathrm{O}_{4}$ [17] nano particle and molecular iodine catalyst.

The organo metallic biodegradable $\mathrm{Zn}[(\mathrm{L}) \text {-Proline }]_{2}$ [17-28] as a catalyst has found very vast applications in reactions such as, aldol condensation [29], cross aldol coupling reactions [30], rearrangement reaction, condensation reaction, usually acts as strong Lewis acid catalyst and dehydrating agent [31].

Von-Pechmann condensation reaction Zn(L-proline) exhibited the highest catalytic activity with regard to the transformation of Salicyaldehyde (1) and ethyl aceto acetate (2) into 3-acetyl-2H-chromen-2-one (4). Zn(L-proline) ${ }_{2}$ which was efficient, inexpensiveness ,eco-friendly as well as easy to handle and re usable catalyst in excellent yields. And its higher solubility in water, insolubility in organic solvents.

The synthesis of 3-(3-(4-chloro phenyl) acryloyl)-2Hchromen-2-one (6) achieved by Using PEG-600 [21] green chemistry approach. In this stage 3-acetyl coumarin were condensed with 4-chloro benzaldehyde through Claisen-Schmidt condensation [33] using piperdine and PEG- 600 as a solvent for both conventional and microwave irradiation respectively. In our work MWI using the PEG-600 [34] like Zn (L-proline) ${ }_{2}$ is nontoxic, eco-friendly, in-expensive,water soluble and potentially recyclable solvent. Based on the careful analysis of the literature, present in- vestigation was aimed to focus on the PEG-600 solvent system. The series of 3-acetyl coumarin and coumarin chalcone com- pounds were synthesized by both conventional and microwave irradiation methods.The synthesized compounds were characterized on the basis of UV-visible, FTIR, 1HNMR and mass spectral data. 


\section{Experimental}

\section{Methods and materials}

The chemicals Salicyladehyde (1), Ethyl acetoacetate (2), Et3N (3), L-Proline (4) ,Zinc acetate (5), 4-chloro benzaledehyde (6), PEG-600 and sodium hydroxide were purchased from Merck (India), Sigma-Aldrich and Avra chemicals. They were used without further purification. Silica gel (TLC and Column grade) was purchased from Merck. The solvents were purified as per the standard procedure reported elsewhere. Melting points were measured in open capillary tubes on Mettler FP51 melting point apparatus and are uncorrected.

The IR spectra were recorded on a Bruker Vertex 70 spectrometer and frequencies were expressed in $\mathrm{cm}^{-1}$. UV-visible spectra were also recorder using Alpha Bruker UV spectraphotometer. The ${ }^{1} \mathrm{H}$ NMR spectra were recorded on a Bruker 400 $\mathrm{MHz}$ instrument in DMSO-d6 or $\mathrm{CDCl}_{3}$ using TMS as an internal standard (chemical shifts were reported in ppm units, coupling constants (J) in $\mathrm{Hz}$ ).

All the compounds were checked for purity by Thin Layer Chromatography (TLC). Mass-spectral analysis was performed by electron ionization on a mass-spectrometer at $20 \mathrm{eV}$. Microwave reactions are carried out commercially available IFB domestic microwave oven having a maximum power out put of $300 \mathrm{~W}$ operating at $2450 \mathrm{~Hz}$.

\section{Synthesis of $\mathrm{Zn}\left[(\mathrm{L})\right.$ proline $_{2}$}

The Zinc amino complex was prepared by adding $\mathrm{Et}_{3} \mathrm{~N}(0.6$ $\mathrm{ml}$ ) to the amino acid (4.34 mmol) in $\mathrm{MeOH}(10 \mathrm{ml})$, after $15 \mathrm{~min}$, followed by zinc acetate $(2.17 \mathrm{mmol})$. After stirring for 1 hour a white precipitate was collected by filtration (98\% yields). (Fig 1)

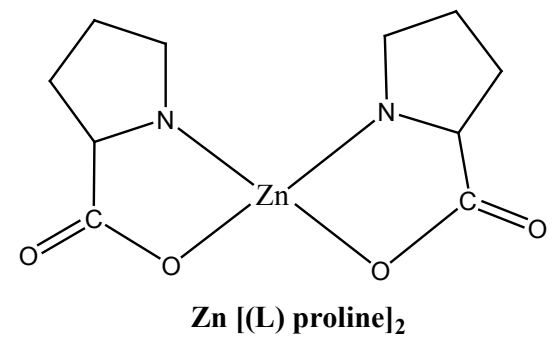

General experimental procedure for Synthesis of 3-acetyl-2H-chromen-2-one (Scheme 1)

Method-A (conventional method): The mixture of Salicyaldehyde (1) (0.2M, $4.28 \mathrm{ml})$ and ethyl aceto acetate (2) $(0.2 \mathrm{M}$, $5.13 \mathrm{ml}$ ) was taken in a beaker, with continuous stirring. After 2 mints 5 to 6 drops of catalyst piperidine was added in the reaction mixture with vigorous shaking. After 15 minutes yellow precipitate was separated out. The precipitate was filtered off, washed and re crystallized with ethanol. The purity of compounds was established on the basis of TLC. Yield: $\mathbf{6 8 - 7 1 \%}$ (M.P. $119-121^{\circ} \mathrm{C}$ ).

Method-B (microwave irradiation method): A mixture of salicyaldehyde (1) (10mmol), ethyl aceto acetate (2) (10 mmol) and $\mathrm{Zn} \mathrm{[(L)-Proline}]_{2}$ (3) (20 mol \%) were subjected to microwave irradiation at 300W for appropriate time 3-5 mints. After completion of reaction, as monitor by TLC, the reaction mixture was cooled to room temperature, water was added as a solvent and stirred for another two minutes, and precipitation was filtered off and re crystallized from ethanol to obtained pure 3-acetyl-2 H-chromen-2-one (4) as yellowish crystal.

Yield: 92 \% (M.P. $119-121{ }^{\circ} \mathrm{C}$ )

Scheme 1
(1)

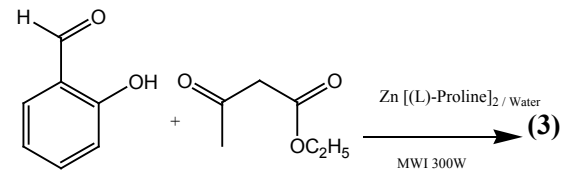

(2)<smiles>CC(=O)c1cc2ccccc2oc1=O</smiles>

(4)
Synthesis of 3-(3-(4-chloro phenyl) acryloyl)-2Hchromen-2-one (Scheme 2 )

Method-A (conventional method): A mixture of 3-acetyl2H-chromen-2-one (4) (0.01mol) and 4-Chloro benzaldehyde (5) $(0.01 \mathrm{~mol})$ and $10 \mathrm{~mL}$ ethanol taken in a round bottom flask. Then 4 to 5 drops of Piperidine was added to it. The reaction mixture allowed refluxing on 5-8 hour at $80^{\circ} \mathrm{C}$ (The formation of product was monitored by TLC). The reaction mixture was poured into ice cold water and then it was neutralized by hydrochloric acid. The yellow colour solid product was filtered and re crystallized by using ethanol as solvent. (Yield: $71 \%$ and melting point: $222-$ $223^{\circ} \mathrm{C}$ )

Method-B (microwave irradiation method): A mixture of 3-acetyl-2H-chromen-2-one (4) $(0.01 \mathrm{~mol})$ and 4-chloro benzaldehyde (5) $(0.01 \mathrm{~mol})$ and $\mathrm{NaOH}(0.02 \mathrm{~mol})$ were grinded in to the mortar. Then it was mixed with $20 \mathrm{~mL}$ of PEG-600. The mixed compounds were taken in a100 mL beaker and it was irradiated with microwave oven for the 3-5 min at $300 \mathrm{~W}$ operating at $2450 \mathrm{~Hz}$ at $30 \mathrm{~s}$ of intervals. After completion of reaction as followed by TLC examination, ice water was added to the reaction mixture and neutralized by an acid. The solid product was obtained, which was filtered, dried and crystallized from an ethanol. The filtrate was evaporated to dryness to remove water leaving behind PEG-600. (Yield - 87.5 \% and melting point: 222$223^{\circ} \mathrm{C}$ ).

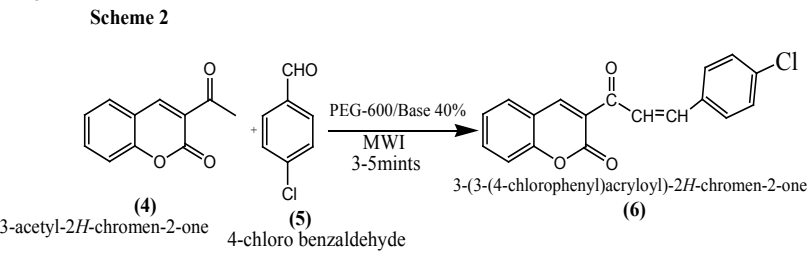

\section{Mechanism of the 3-acetyl-2H-chromen-2-one formation using $\mathrm{Zn}\left[(\mathrm{L})-\right.$ Proline $_{2}$ as a Catalyst (Scheme 1)}

The mechanism of formation of 3-acetyl-2H-chromen-2-one can be visualized as shown in Scheme 1. Probably the reaction 
initiates by nucleophilic attack of nitrogen of $\mathrm{Zn}$ (L-proline) complex on 2-hydroxy Benzaldehyde (1) to form A, in which aldehydic oxygen is bonded with $\mathrm{Zn}(\mathrm{L} \text {-proline })_{2}$ complex. A is then converted to $\mathrm{B}$ through the displacement of lone pair of electron and opening of carbon-oxygen bond.

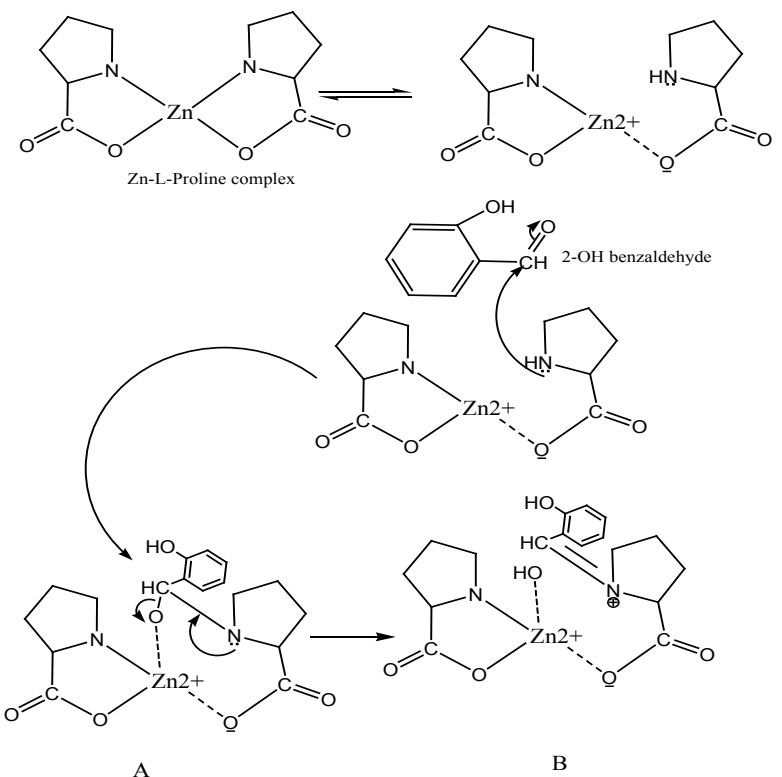

The Active Methylene Carbon containing Ethyl aceto acetate $\mathrm{X}$ which on enlolated,Carbon-carbon double bond of enolized diketone $\mathrm{Y}$ then attacks on carbon of $\mathrm{B}$ to give $\mathrm{C}$, ethanol as a leaving group in this stage then $\mathrm{D}$ undergoes cleavage process to expel out $\mathrm{Zn}$ (L-proline)2 complex (3) and water so as to result in 3-acetyl-2H-chromen-2-one (4).

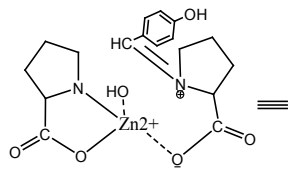

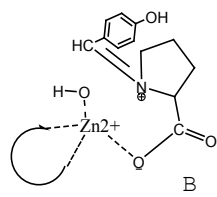<smiles>C#COC(=O)C=C(C)O</smiles><smiles>COC=C(C)O</smiles>

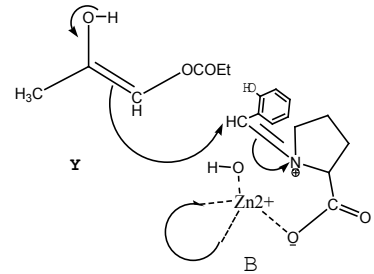

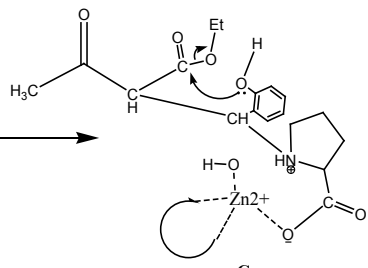

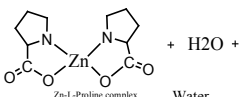

(3)

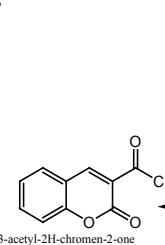

(4) $\stackrel{\oplus}{\mathrm{H} S h i f t}$

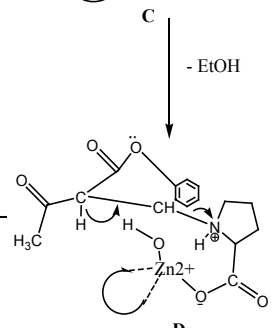

\section{Results}

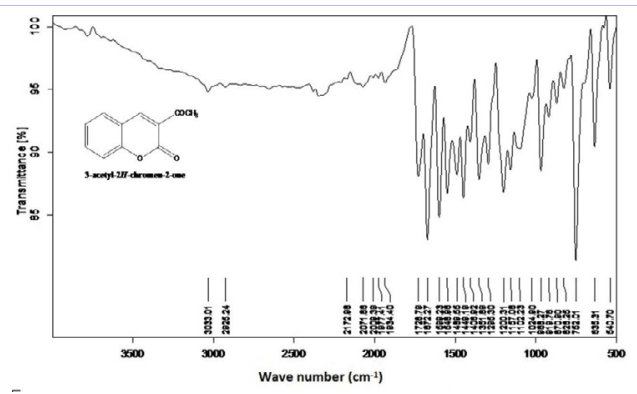

Figure 1: FT-IR Spectrum of 3-acetyl-2H-chromen-2-one .

\begin{tabular}{|c|c|c|}
\hline Melting point : & $119-121^{\circ} \mathrm{C}$ & $\mathrm{C}_{11} \mathrm{H}_{8} \mathrm{O}_{3}$ \\
\hline $\begin{array}{l}\text { UV-visible } \quad(\lambda \\
\text { max: } \mathrm{nm}):\end{array}$ & $\begin{array}{l}298\left(\pi \rightarrow \pi^{*} \text { transition }\right) \\
340\left(n \rightarrow \pi^{*} \text { transition }\right)\end{array}$ & \\
\hline FTIR $\left(\mathrm{cm}^{-1}\right):$ & $\begin{array}{l}\text { 2945(Aromatic C-H stretching), } \\
\text { 1728.29(C=O(ester)), 1627.29 } \\
\text { (C=O(Exo cyclic ketone)), 1599.23 C=C } \\
\text { str.(Aromatic),1351(C-Cstr), 752(C-H } \\
\text { out plane bending), } 1157.28 \text { (C-O str). }\end{array}$ & (Fig: 1) \\
\hline 1H NMR(ppm) : & $\begin{array}{l}\text { d } 2.51(\mathrm{~s}, 3 \mathrm{H}, \mathrm{CH} 3), 7.32- \\
7.95(\mathrm{~m}, 4 \mathrm{H}, \text { Benzo fused coumarin- } \mathrm{H}) \text {, } \\
8.65(\mathrm{~s}, 1 \mathrm{H}, \text { Coumarin- } \\
\text { H). }\end{array}$ & (Fig: 2) \\
\hline Mass $(\mathrm{m} / \mathrm{z})$ : & Calculated M.W 188.18 & $\begin{array}{l}\text { Ob-served } \\
\text { M.W } 189.60 \\
\text { (Fig: 3) }\end{array}$ \\
\hline
\end{tabular}

Table 2: Spectral details of 3-(3-(4-Chloro phenyl)acryloyl)-2Hchromen-2-one (6)

\begin{tabular}{|c|c|c|}
\hline Melting point : & $246-249^{\circ} \mathrm{C}$ & \\
\hline $\begin{array}{l}\text { UV-visible }(\lambda \\
\text { max: } \mathrm{nm})\end{array}$ & $306(\pi \rightarrow \pi *$ transition $)$ & \\
\hline FT-IR $\left(\mathrm{cm}^{-1}\right):$ & $\begin{array}{l}1618, v(\mathrm{C}=0, \alpha, \beta \text {-unsaturated } \\
\text { ketone }), 1742, v(\mathrm{C}=0 \text {, lactone } \\
\text { carbonyl of coumarin }) .\end{array}$ & (Fig: 4) \\
\hline $\begin{array}{l}{ }^{1} \mathrm{H} \text { NMR } \\
\text { (DMSO- } d_{6} 400 \\
\text { MHz): }\end{array}$ & $\begin{array}{l}\delta 6.86\left(1 \mathrm{H}, \mathrm{m}, \mathrm{C}_{6}-\mathrm{H}\right), \delta 7.12(2 \mathrm{H}, \mathrm{d}, \\
\text { p-substituted phenyl ring), } \delta 7.23 \\
(1 \mathrm{H}, \mathrm{m} \text {, aromatic protons), } \delta 7.39 \\
(2 \mathrm{H}, \mathrm{m} \text {, aromatic proton), } \delta 7.63(2 \mathrm{H}, \\
\text { d, p-substituted phenyl ring), } \delta 7.88 \\
(1 \mathrm{H}, \mathrm{d}, J=7.8 \mathrm{CH}=\mathrm{CH} \text { - protons), } \delta \\
7.90(1 \mathrm{H}, \mathrm{d}, \mathrm{CH}=\mathrm{CH} \text { - protons), } \delta 8.52 \\
\left(1 \mathrm{H}, \mathrm{s}, \mathrm{C}_{4}-\mathrm{H}\right) .\end{array}$ & (Fig: 5) \\
\hline $\begin{array}{l}{ }^{13} \mathrm{C}-\mathrm{NMR} \\
\left(\mathrm{CD}_{3} \mathrm{OD}, 400\right. \\
\mathrm{Hz}):\end{array}$ & $\begin{array}{l}\text { d 183.7, 159.4, 153.0, 147.2, 142.2, } \\
\text { 134.2, 133.5, } \\
\text { 133.3, 129.0, 129.0, 128.7, 128.7, } \\
\text { 128.3, 127.9, 125.4, 125.4, 118.1, } \\
\text { 116.1 ppm. }\end{array}$ & (Fig 6) \\
\hline ESI-MS $(m / z):$ & Calculated M.Wt 310.04 & $\begin{array}{l}\text { Ob-served } \\
\text { M.Wt } \\
310.6,312.7 \\
\text { (Fig: 7) }\end{array}$ \\
\hline
\end{tabular}




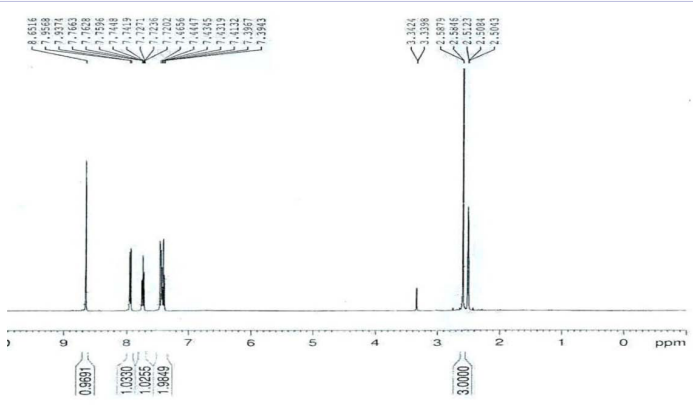

Figure 2: ${ }^{1} \mathrm{H}$ NMR Spectrum of 3-acetyl-2H-chromen-2-one.

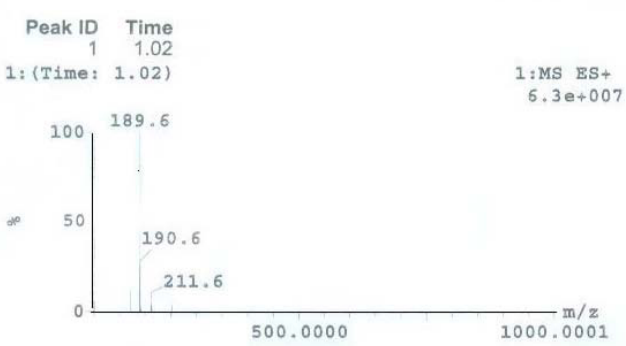

Figure 3: Mass Spectrum of 3-acetyl-2H-chromen-2-one.

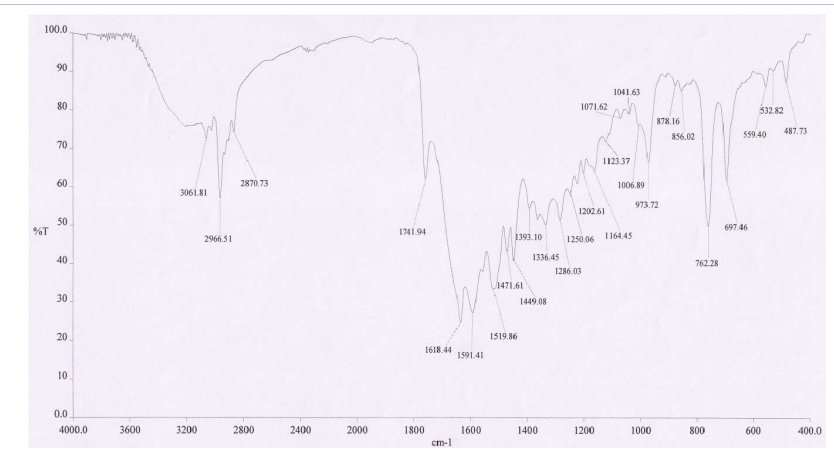

Figure 4: FT-IR Spectrum of 3-(3-(4-Chloro phenyl)acryloyl)-2H-chromen-2-one.

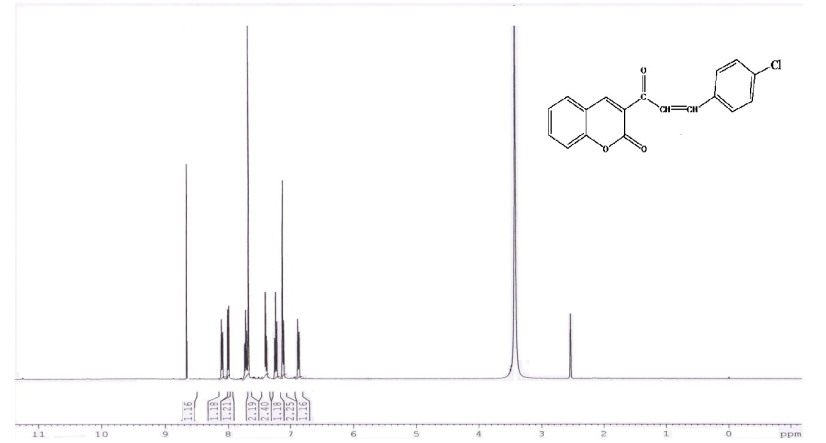

Figure 5: ${ }^{1} \mathrm{H}$ NMR Spectrum of 3-(3-(4-Chloro phenyl)acryloyl)-2Hchromen-2-one.

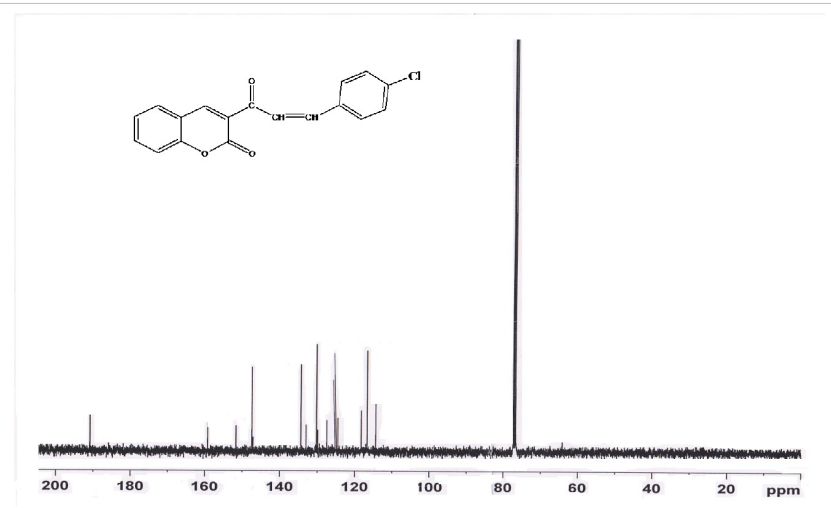

Figure 6: ${ }^{13} \mathrm{C}$ NMR Spectrum of 3-(3-(4-Chloro phenyl)acryloyl)-2Hchromen-2-one.

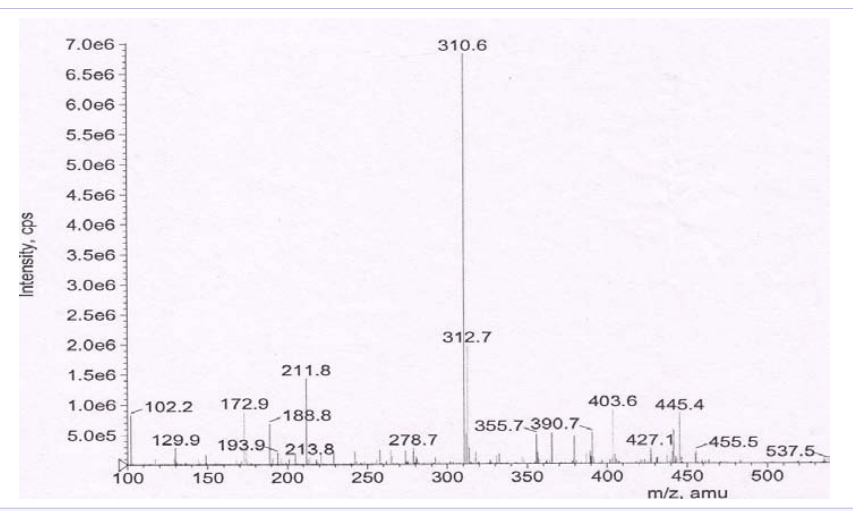

Figure 7: Mass Spectrum of 3-(3-(4-Chloro phenyl)acryloyl)-2H-chromen-2-one.

\section{Discussion}

A mixture of Salicyaldehyde (1) and ethyl aceto acetate (2) was subjected to microwave irradiation $(300 \mathrm{~W})$ in presence of Zn [(L)-Proline $]_{2}$ (3) under solvent free condition with different mol\%. (Scheme 1). The Progress of reaction was checked by chromatography (TLC). Optimization of reaction condition was achieved by using varying amounts of $\mathrm{Zn}[(\mathrm{L}) \text {-Proline }]_{2}$ catalyst and best results of yields could be obtained by using $20 \mathrm{~mol}$ $\%$ of $\mathrm{Zn}[(\mathrm{L}) \text {-Proline }]_{2}$ catalyst. Increasing the ratio, above 20 mol\% of $\mathrm{Zn}[(\mathrm{L}) \text {-Proline }]_{2}$ was found to increase rate of reaction but afforded products in low yield due to the formation of side products. (Table 3).

In summary ,for synthesis of 3-acetyl-2H-chromen-2-one by Pechmann condensation is highly efficient as it avoid use of organic solvents at any stage of reaction, under microwave irradiation technique at very low power $(300 \mathrm{~W})$ and presence of organo metallic biodegradable $\mathrm{Zn}\left[(\mathrm{L})-\right.$ Proline $_{2}$ as a catalyst.

The (Scheme 1) progressive of the reaction employed $\mathrm{Zn}$ $[(\mathrm{L}) \text {-Proline }]_{2}$ at different Optimised condition furnishing very good yield $92 \%$ instead of acid /base catalysts. Our investigation revealed that the catalytic activity of various acidic/basic catalysts in water was found to be in the order Zn (L-proline) $)_{2}>$ 
Table 3: Optimization of reaction condition for synthesis of 3-acetyl-2Hchromen-2-one under Solvent free condition by microwave irradiation technique at low power $(300 \mathrm{~W})$ using $\mathrm{Zn}[(\mathrm{L})-\text { Proline }]_{2}$ catalyst.

\begin{tabular}{|c|c|c|}
\hline Catalyst & Mol \% & Yield \\
\hline $\mathrm{Zn}[(\mathrm{L})-\text { Proline }]_{2}$ & 5 & Below 20\% \\
\hline $\mathrm{Zn}[(\mathrm{L})-\text { Proline }]_{2}$ & 10 & $42.2 \%$ \\
\hline $\mathrm{Zn}[(\mathrm{L})-\text { Proline }]_{2}$ & 15 & $69 \%$ \\
\hline $\mathrm{Zn}[(\mathrm{L})-\text { Proline }]_{2}$ & 20 & $92 \%$ \\
\hline $\mathrm{Zn}[(\mathrm{L})-\text { Proline }]_{2}$ & 25 & $84.3 \%$ \\
\hline $\mathrm{Zn}[(\mathrm{L})-\text { Proline }]_{2}$ & 30 & $76.5 \%$ \\
\hline
\end{tabular}

piperidine $>$ L-proline $>$ diethyl amine $>\mathrm{FeCl}_{3}>\mathrm{ZnCl}_{2}$ in terms of yield and selectivity.

However, in polar protic solvents $\mathrm{MeOH}$, EtOH, and $\mathrm{AcOH}$ relatively high yield of the product (74-78\%) was obtained under reflux condition in more period of time, whereas when reaction was performed in water in the presence of $\mathrm{Zn}$ (L-proline) $)_{2}$, it completed within 15 min whole reaction with increase in yield of the product (92\%) (Table 4)

UV absorption and FT- IR spectra of compound (4) and (6) has been provided a preliminary idea in confirmation the formation of product. According to the UV spectrum, presence of peaks at $286 \mathrm{~nm}$ and $306 \mathrm{~nm}$ clearly showed that the compound (6) has $-\mathrm{CH}=\mathrm{CH}-$ group and hetero atom respectively. According to the FT-IR, presence of peak at $1627.29 \mathrm{~cm}^{-1}$ has clearly, the utilization of starting materials transform in to the product. Further, the corresponding peaks at 2945, 1728.29,1627.29,1599.23,1351,7 52 and $1157.28 \mathrm{~cm}^{-1}$ have been related to $-\mathrm{Ar} \mathrm{C}-\mathrm{H}$ str, $\mathrm{C}=\mathrm{O}$ ester (str), C=O Exo cyclic ketone (str), C=Cstr.(Aromatic), C-C str. (exo cyclic),(C-H out plane bending) and (C-O str) respectively in the compound (4) (Fig.1). The concerned mass of the compound (4) is in good agreement with the observed $(189.6 \mathrm{~m} / \mathrm{z})$ and calculated value $(188.18 \mathrm{~m} / \mathrm{z})$. (Fig.3) similarly, proton NMR strongly revealed for the formation of the product by its $\delta$ value at 2.51, 7.32-7.95, and 8.65ppm corresponding to the aliphatic $\mathrm{C}-\mathrm{H}, \mathrm{Ar}-\mathrm{H}$ and Benzo fused coumarin-H protons of compound (4) were mentioned in (Fig.2).

Similarly, (Scheme-2) to the FTIR, presence of peak at 1618 $\mathrm{cm}^{-1}$ has clearly, the utilization of starting materials transform in to the product. Further, the corresponding peaks at 1618, $v(\mathrm{C}=0, \alpha, \beta$-unsaturated ketone $), 1742, v(\mathrm{C}=0$, lactone carbonyl of coumarin) respectively, in the compound (6). (Fig.4) The concerned mass of the compound (6) is in good agreement with the observed (310.6 m/z) and calculated value (310.04 m/z) (Fig.7).

Table 4: Different solvents effect on the synthesis of 3-acetyl-2Hchromen-2-one in the presence of $\mathrm{Zn}$ (L-proline) ${ }_{2}$ Catalyst.

\begin{tabular}{|c|c|c|}
\hline Solvent & Time & Yield (\%) \\
\hline $\mathrm{H}_{2} \mathrm{O}$ & 15 & 92 \\
\hline $\mathrm{MeOH}$ & $75-80$ & 78.5 \\
\hline $\mathrm{EtOH}$ & $92-98$ & 78.2 \\
\hline $\mathrm{AcOH}$ & 120 & $74-76$ \\
\hline
\end{tabular}

Similarly, proton NMR strongly revealed for the formation of the product by its $\delta$ value at $\delta 6.86\left(1 \mathrm{H}, \mathrm{m}, \mathrm{C}_{6}-\mathrm{H}\right), \delta 7.12(2 \mathrm{H}, \mathrm{d}, J=$ 7.2 , p-substituted phenyl ring), $\delta 7.23(1 \mathrm{H}, \mathrm{m}, \mathrm{Ar}-\mathrm{H}), \delta 7.39(2 \mathrm{H}$, $\mathrm{m}$, aromatic proton), $\delta 7.63(2 \mathrm{H}, \mathrm{d}, J=7.2$, p-substituted phenyl ring), $\delta 7.88(1 \mathrm{H}, \mathrm{d}, J=7.8, \mathrm{CH}=\mathrm{CH}-$ protons), $\delta 7.90(1 \mathrm{H}, \mathrm{d}, J=$ 7.8, $\mathrm{CH}=\mathrm{CH}-$ protons $), \delta 8.52\left(1 \mathrm{H}, \mathrm{s}, \mathrm{C}_{4}-\mathrm{H}\right)$ of compound 6 were mentioned in (Fig.5). [13]. C NMR (DMSO- $d_{6} 100 \mathrm{MHz}$ ): $\delta 114.8$ (C-4a), 116.5 (C-8), 118.6 (C-10, - $\mathrm{CO}-\mathrm{CH}=$ ), 124.2, 125.1, 126.2, $127.9,129.8,130.0,133.5,134.6$ (8 different types of aromatic carbons), 147.1 (C-11, -CH=CH-), 147.6(C-4), 151.5(C-8a), 159.7 $(\mathrm{C}=0$, lactone carbonyl of coumarin), $190.2(\mathrm{C}=0, \alpha, \beta$-unsaturated ketone). (Fig.7)

\section{Conclusions}

* In our conclusion, clear that first step, Pechmann condensation reaction $\mathrm{Zn}$ (L-proline), exhibited the highest catalytic activity with regard to the transformation of Salicyaldehyde (1) and ethyl acetoacetate (2) into 3-acetyl-2H-chromen-2-one (4).

* Zn (L-proline) ${ }_{2}$ which was efficient, inexpensiveness ,ecofriendly as well as easy to handle and re usable catalyst in excellent yields and its higher solubility in water, insolubility in organic solvents.

* Similarly, Second step the synthesis of 3-(3-(4-Chloro phenyl) acryloyl)-2H-chromen-2-one (6) achieved by using PEG-600 green chemistry approach. In this stage 3-acetyl coumarin (4) were condensed with 4-chlorobenzaldehyde (5) through Claisen-Schmidt condensation using piperdine and PEG- 600 as a solvent for both conventional and microwave irradiation respectively.

* In our work MWI using the PEG-600 like Zn (L-proline) is non-toxic ,eco-friendly, in-expensive, water soluble and potentially recyclable solvent. Generally most of the researchers have been synthesized by 3 -acetylcoumarin and coumarinyl chalcones using by Piperidine as catalyst. But Piperidine as catalyst is used hazarder us as well as dangerous to handle. Therefore both step used amino acid Zn (L-proline) $)_{2}$ catalyst and PEG 600 solvent fulfils the green chemistry approaches.

* The chemical structures of compounds (4) and (6) have been confirmed using standard spectral techniques viz., FT-IR, UV-visible, Mass and ${ }^{1} \mathrm{H}-\mathrm{NMR}$ spectra and were found to be in agreement with the chemical structures as expected.

\section{References}

1. Omprakash S Chavan, Santosh A Jadhav, Mahesh G Shioorkar Shivaji B Chavan, Mohmmad A. Baseer and Devanand B. Shinde, Microwave assisted solvent free synthesis of coumarins using $\mathrm{Zn}[(\mathrm{L})$-Proline 2 catalyst. Rasiyan J Chem. 2015;8(2):194-197.

2. Pangal A, Gazge M, Mane V, Shaikh JA. Various Pharmacological Aspects of Couamrin Derivatives: A Review. IJPRBS. 2013;2(6):168194. 
3. Anees Pangal, Gazge Muiz, Mujahid Yusufi, Gauri Devasthale, Ejazuddin Khan. In Vitro Investigation of Antibacterial Activity of Novel 3-Acetylcoumarin Schiff Bases and Their Molecular Docking Studies. Int J pharm res scholars. 2014;3(1):696-703.

4. Nikhil B, Shikha B, Anil P, Prakash NB. Diverse pharmacological activities of 3-Substituted coumarins: A review International Research Journal of Pharmacy. 2012;3(7):24-29.

5. Mashelkar UC, Audi AA. J Indian Chem Soc. 2005;82:254.

6. H Von Pechmann and C Duisberg. Chem Tech Ber. 1884;17:927.

7. R Adams, TE Bockstahler. Preparation and Reactions of o-Hydroxycinnamic Acids and Ester. J Am Chem Soc. 1952;74(21):5346-5348. doi: 10.1021/ja01141a038.

8. SB Kadin. Reduction of Conjugated Double Bonds with Sodium Borohydride. J Org Chem. 1966;31(2):620-622. doi: 10.1021/ jo01340a523.

9. JR Johnson. Review of Perkin Reaction. Org React. 1942;1:210

10.RL Shirner. Review of Reformatsky (Reformatskii) Reaction. Org React. 1942;1:1.

11.I Yavari, R Hekmat-shoar, A Zonouzi. A new and efficient route to 4-carboxymethylcoumarins mediated by vinyltriphenylphosphonium salt. Tetrahedron Lett. 1998;39(16):2391-2392.

12.Sethna S, Phadke R. The Pechmann Reaction. Chapter 1, in Organic Synthesis, John Wiley \& Sons, Inc. New York. 1953;7(1):1883.

13. Sudarshan Das, Adinath Majee, Alakananda Hajra. A convenient synthesis of coumarins using reusable ionic liquid as catalyst. Green Chemistry Letters and Review. 2011;4(4):349-353. doi:10.1080/175 18253.2011.572296

14. Nagnnath D Kokare, Jaiprkash N, Sangshetti, Devanand B Shinde, Oxalic acid catalyzed solvent-free one pot synthesis of coumarins. Chinese Chem Let. 2007;18(11):1309-1312.

15.Seyed Meysam Baghbanian, Maryam Farhang. CuFe204 Nanoparticles: A Magnetically Recoverable and Reusable Catalyst for the Synthesis of Coumarins via Pechmann Reaction in Water Syn Comm. 2014;44(5):697-706. doi: 10.1080/00397911.2013.835423.

16. Jami De Grote, Stephan Tyndall, Koon Fai Wong, MVA Parris Synthesis of 7-alkoxy-4-Trifluoromethyl coumarins via the von Pechmann reaction catalyzed by molecular iodine. Tetrahedron Lett. 2014;55(49):6715-6717

17. Tamis Darbre, M Machuqueiro. Zn-Proline catalyzed direct aldol reaction in aqueous media. Chem Comm. 2003;(9):1090-1091.

18. Kofoed J, Machuqueiro M, Reymond JL, Darbre T. Zincproline catalyzed pathway for the formation of sugars. Chem Commun. 2004;35(13):1540-1541. doi: 10.1039/ b404465g.

19. Sivamurugan V, Deepa K, Palanichamy M, Murugesan V. [(L) Proline]2 Zn Catalysed Synthesis of 1,5-Benzodiazepine Derivatives Under Solvent-Free Condition. Synth Commun. 2004;34(21):38333846. Doi:10.1081/ SCC-200034752.

20. Sivamurugan V, Kumar RS, Palanichamy M, Murugesan V. Synthesis of hantzsch 1, 4-dihydropyridines under solvent-free condition using zn[(L) proline]2 as lewis acid catalyst. Journal of Heterocyclic. Chemistry. 2005;42(5):969-974. Doi: 10.1002/ jhet.5570420534.

21. Kofoed J, Reymond JL, Darbre T. Prebiotic carbohydrate synthesis: zinc-proline catalyzes direct aqueous aldol reactions of $\alpha$-hydroxy aldehydes and ketones. Org Biomol Chem. 2005;3(10):1850-1855.

22. Ruben FL, Kofoed J, Machuqueiro M, Darbre T. A Selective Direct Aldol Reaction in Aqueous Media Catalyzed by Zinc-Proline. J Org Chem. 2005;2005(24):5268-5276. doi:10.1002/ ejoc.200500352.

23. Sivamurugan V, Vinu A, Palanichamy M, Murugesan V. Rapid and cleaner synthesis of 1,4-dihydropyridines in aqueous medium. J Heteroat Chem. 2006;17(4):267-271. doi: 10.1002/ hc.20197.

24. Kofoed J, Darbre T, Reymond JL. Dual mechanism of zincproline catalyzed Aldol reactions in water. Chem Commun. 2006;14(14):1482-1484.

25. Reddy KR, Rajasekhar CV, Krishna GG. Zinc-Proline Complex: An Efficient, Reusable Catalyst for Direct Nitroaldol Reaction in Aqueous Media. Synth Commun. 2007;37(12):1971-1976. doi: 10.1080/ 00397910701354731.

26. Heravi MM, Tehrani MH, Bakhtiari K, Oskooie HA. A powerful catalyst for the very fast synthesis of quinoxaline derivatives at room temperature. Catal Commun. 2007;8(9):1341-1344.

27. Kidwai M, Jain A, Bhardwaj S. 1, 4-Addition of Terminal Alkynes to Conjugated Enones in Water Using Green Catalyst Bis [(l) prolinato-N,O] Zn-An Environmentally Benign Protocol. Catal Lett. 2010;141(1):183-190. doi:10.1007/ s10562-010-0451-8.

28. Mazaahir Kidwai, Arti Jain, Roona Poddar. Zn [(1)proline]2 in water: A new easily accessible and recyclable catalytic system for the synthesis of pyrazoles. J Organomet Chem. 2011;696(10):1939-1944.

29. Guo Sheng-Rong, Yuan Yan Qin, Wang Li Jin. Copper (I)-catalyzed Synthesis of Aryl, Heteroaryl and Vinyl Sulfides in Aqueous Twophase System. Chem Res Chinese Universities. 2011;27(3):417-421.

30.Zeba N. Siddiqui TNM Musthafa. An efficient and novel synthesis of chromonyl chalcones using recyclable Zn(L-proline)2 catalyst in water. Tetrahedron Lett. 2011;52(31):4008-4011. doi:10.1016/j. tetlet.2011.05.118.

31. Mazaahir Kidwai, Arti Jain, Roona Poddar. Zn [(L) proline]2 in water: A new easily accessible and recyclable catalytic system for the synthesis of pyrazoles. J Orgno Mett Chem. 2011;696(10):1939-1944. doi:10.1016/j.jorganchem.2010.09.012.

32. Alvarez Mde L, Zarelli VE, Pappano NB, Debattista NB. Bacteriostatic action of synthetic polyhydroxylated chalcones against Escherichia coli. Biocell. 2004;28(1):31-34.

33. BS Dawane, YB Vibhute, SG Konda, MR Mali. Synthesis of Some New 3-(Substituted phenyl)- 5- (9-anthryl)- 2-pyrazolines, 1-Phenyl-3(substituted phenyl)-5-(9-anthryl)- 2-pyrazolines and 2-(9-Anthryl)4-(substituted phenyl)-1, 5- benzothiazepines as Antibacterial Agents. Asian J Chem. 2008;20(6):4199-4204.

34.MR Jayapal, K Sreenivasa Prasad, NY Sreedhar. Synthesis and Characterization of 2,6-Dihydroxy Substituted Chalcones Using PEG400 as a Recyclable Solvent. J Pharm Sci \& Res. 2010;2(8):450-458. 